\title{
Self-perceived competencies in the diagnosis and treatment of mental health disorders among general practitioners in Lima, Peru
}

\author{
Jessica Hanae Zafra-Tanaka ${ }^{1}$, Kevin Pacheco-Barrios ${ }^{2,3}$, Fiorella Inga-Berrospi ${ }^{4}$ and Alvaro Taype-Rondan ${ }^{3^{*}}$
}

\begin{abstract}
Aim: To assess the self-perceived competencies in diagnosing and treating patients with mental health disorders, among recently graduated general practitioners (GPs) from Lima, Peru.

Methods: A cross-sectional study was performed in April 2017 at a General Practitioner's meeting held for those who were going to perform the social service, by the Peruvian College of Physicians in Lima. Attendees were invited to answer a questionnaire that evaluated their self-perception of competence in diagnosing and treating four different mental health disorders; major depression, anxiety disorder, alcohol dependence, and schizophrenia.

Results: Out of 434 evaluated GPs, the following percentages were self-perceived as competent in their adequate diagnosis of depression (70.5\%), anxiety (73.3\%), alcohol dependence (67.6\%), and schizophrenia (62.0\%). Concerning pharmacological treatment, these percentages were 46.6, 47.5, 39.0 and 37.6\%, respectively. Referring to all the studied mental disorders, $41.6 \%$ of participants self-perceived competence in providing an adequate diagnosis, 36.1\% in providing non-pharmacological treatment, and 20.1\% in providing pharmacological treatment.

Conclusion: The rate of adequate self-perceived competences was higher for diagnosis than for treatment of patients with mental health disorders. These results highlight the importance of designing and implementing interventions to improve medical education so as to develop the skills necessary to confront mental health disorders.
\end{abstract}

Keywords: Mental health, Psychiatry, Self-perceived competence, Skills, Undergraduate education

\section{Background}

The burden of mental health disorders continues to grow over time, with $22.7 \%$ of people worldwide now living with a mental health disability [1]. Regrettably, the number of specialized mental health professionals is insufficient to confront this problem, this is predominantly tangible in developing countries where the ratio of physicians to patients is much more disparate $[2,3]$. Thus, it is necessary for primary health care personnel such as general practitioners (GPs), psychologists, nurses, and

\footnotetext{
* Correspondence: alvaro.taype.r@gmail.com

${ }^{3}$ Unidad de Investigación para la Generación y Síntesis de Evidencias en

Salud, Universidad San Ignacio de Loyola, Lima, Peru

Full list of author information is available at the end of the article
}

technical staff to be able to diagnose and treat mental health disorders.

In Peru, 6 out of 24 regions have no psychiatrist in the public health care system, and in the regions that do have any psychiatrist, they are generally restricted to large cities [3] and urban areas, leaving rural areas without access to mental health care. GPs are usually in charge of diagnosing and treating patients with mental health disorders in primary care $[4,5]$. Many GPs working in primary care are currently performing the Urban Rural Marginal Internship Program (called SERUMS for its acronym in Spanish), which is a social service mandatory for those who want to work for the state or carry out medical residency and studies in Perú $[6,7]$. The SERUMS program takes place in underserved rural

(c) The Author(s). 2019 Open Access This article is distributed under the terms of the Creative Commons Attribution 4.0 International License (http://creativecommons.org/licenses/by/4.0/), which permits unrestricted use, distribution, and reproduction in any medium, provided you give appropriate credit to the original author(s) and the source, provide a link to the Creative Commons license, and indicate if changes were made. The Creative Commons Public Domain Dedication waiver (http://creativecommons.org/publicdomain/zero/1.0/) applies to the data made available in this article, unless otherwise stated. 
areas where there are no specialists, so the GPs working on their SERUMS are in charge of managing mental health disorders. This makes it essential for recently graduated GPs to receive suitable mental health care training and education in medical schools.

Worldwide, most studies on mental health capacities among GPs have assessed their knowledge [8-10], while few have assessed their competencies on the diagnosis or treatment of mental disorders [11-16], none of them in Peru. These studies have found low self-perceived competencies regarding this issue. Even though these studies have evaluated heterogeneous groups of GPs, none of them have assessed recently graduated GPs, particularly relevant in Peru.

This scarcity of information makes it difficult to develop and implement educational interventions to improve the diagnosis and treatment skills of mental health disorders among GPs in Peru. For this reason, the objectives of the present study were: 1) to assess the selfperceived competencies in the diagnosis and treatment of mental health disorders among recently graduated GPs from Lima, Peru, 2) to evaluate the association between self-perceived competencies and the university were the GP studied, and 3) to explore aspects to be improved in undergraduate psychiatry courses. This will provide decision makers and professors a general picture of the needs GPs perceive and help identify which universities are the ones that need to improve more.

\section{Method}

\section{Type of study and population}

A cross-sectional study was performed in which selfadministered surveys were presented to GPs attending the "Sixth National SERUMS Convention" ("VI Convención Nacional SERUMS"), a convention organized by The Young Physicians Committee ("Comité Médico Joven") of the Peruvian College of Physicians in April 2017. This convention aimed to provide general information and insights of the SERUMS program to the GPs who planned to form part of the program in 2017.

All GPs who registered their attendance at the convention and agreed to participate in the study were included. For data analysis, those who did not complete their undergraduate studies in Lima, or who had not recently graduated (in the last year), or did not completely fill out the variables of interest in the survey, were excluded.

\section{Study procedures}

Trained personnel handed the study survey to all the participants at the time they entered the convention. Each GP was given an oral explanation of the study along with a summary of the study and the survey. The survey was anonymously completed before the start of the convention and during the recess. The researchers were present to response any questions the participants might have regarding the survey and to collect the questionnaires once they were finished.

The data was double-entered by different researchers in an independent fashion. A researcher who did not participate in this process cross-checked the doubleentered data, and in cases of discrepancies, the surveys were re-evaluated to correct any mistakes.

\section{Survey}

An ad hoc survey was created for the study, which included the following four sections: 1) sociodemographic data, 2) self-perception of competencies in mental health, 3) self-perception of competencies in general medicine, and 4) self-perception of competencies in obstetric care. For this study, we used data from the first two sections.

The mental health section assessed self-perceived competencies in the four mental health disorders with the highest worldwide burden in terms of years lived with a disability, as reported by the World Health Organization [1]: major depression, anxiety disorder, alcohol dependency, and schizophrenia. There was also a subsection included with five questions which aimed to assess areas of potential improvement in undergraduate psychiatry courses. To assure the content validity and ensure that the questions proposed were adequate and understandable, our survey was reviewed by psychiatrists and by recently graduated GPs who did not take part in the study.

\section{Study variables}

\section{Perception of competencies in mental health}

Four mental health disorders were studied: major depression, anxiety disorder, alcohol dependency, and schizophrenia. For the first three disorders, the following competencies were assessed: diagnosis, nonpharmacological treatment (e.g. psychoeducation), and pharmacological treatment; while only diagnosis and pharmacological treatment were assessed for schizophrenia.

Each competency was assessed using the following statement: "I have adequate competencies for ..." and five possible responses (strongly disagree, disagree, neutral, agree, and strongly agree). We considered self-perception of adequate competence when the GP answered "agree" or "strongly agree" on all the statements for each variable assessed (diagnosis, pharmacological treatment, and nonpharmacological treatment). This was a dichotomous variable with possible answers "yes" or "no".

\section{Aspects to be improved in undergraduate psychiatry courses}

We also asked about aspects to be improved in undergraduate psychiatry courses using the following question: 
"The psychiatry course in my faculty should have ..." with five aspects (more critical reading of scientific articles, more theoretical classes, more hours in the outpatient clinic, more contact with patients, and more teaching about patient treatment). For each aspect, five possible answers were proposed (strongly disagree, disagree, neutral, agree, and strongly agree).

\section{Other variables}

Other variables evaluated were age, sex, year in which the GP completed their internship, and the university where the GP studied medicine. Age was categorized in tertiles ( 22 to 25,26 , and 27 to 42 years) to facilitate the analysis and interpretation of data.

\section{Statistical analysis}

For the descriptive analysis of categorical variables, absolute and relative frequencies were used. For the sociodemographic quantitative variables, means and their respective standard deviations were reported.

In addition, we assessed the association between the university where the GP studied and three outcomes: self-perception of adequate competence in the diagnosis, non-pharmacological, and pharmacological treatment of all mental health disorders. For this, prevalence ratios $(\mathrm{PR})$ and their $95 \%$ confidence intervals $(95 \% \mathrm{CI}$ ) were calculated using Poisson regression with robust variance. We also performed power analysis to evaluate the probability of making type 2 error. In order to estimate the power of each of our associations, we estimated power for a PR of 1.5, a level of significance of $95 \%$, and a proportion of the comparison group of $40 \%$ for diagnostic and for non-pharmacological management, and of $20 \%$ for pharmacological management; according to the rate of these outcomes.

Also, we performed a Kruskal Wallis test to evaluate the differences between the universities when analyzing our primary outcomes as continuous variables. In order to so, we coded the five possible answers as follows: strongly disagree $=1$, disagree $=2$, neutral $=3$, agree $=4$, and strongly agree $=5$. Using these values, we estimated a mean score for each outcome (diagnostics, pharmacological treatment, and non-pharmacological treatment) by adding all the values obtained for each medical condition (major depression, anxiety disorder, alcohol dependency, and schizophrenia), and dividing it by the number of conditions. We used the Dunn test as a post hoc analysis to perform pairwise comparison.

Given the small proportion of missing data (0.9 to 3\% for the questions that aimed to assess competence), we decided that, when data was not available for certain participant, we would not include it in the analysis. That said, we did not perform any type of imputation when data was not available for certain participant, we would not include it in the analysis. That said, we did not perform any type of imputation. Analyses were performed using Stata software v14.0.

\section{Results}

Of the 688 GPs who were given the survey during enrollment at the convention, $520(75.6 \%)$ responded. Of these, 66 were excluded because they had undergone undergraduate studies outside Lima, and 20 that were not recently graduated GPs (i.e., those who finished medical school before 2016), leaving 434 for analysis. This represents $33.2 \%$ of all GPs recently graduated from universities in Lima according to the Peruvian College of physicians. Among the evaluated GPs, the mean age was $26.01 \pm 2.8$ years, and $246(56.7 \%)$ were female (Table 1$)$.

With respect to clinical depression, 296 (70.3\%) GPs perceived themselves to be adequately competent to perform an adequate diagnosis, 227 (53.0\%) to provide nonpharmacological treatment, and 198 (46.9\%) to provide pharmacological treatment. With respect to anxiety disorder, $311(73.5 \%)$ perceived themselves to be sufficiently competent to perform an adequate diagnosis, 259 (60.7\%) to provide non-pharmacological treatment, and 205 (47.9\%) to provide pharmacological treatment. Regarding alcohol dependency disorder, 289 (67.7\%) perceived themselves to be sufficiently competent to perform an adequate diagnosis, $249(58.0 \%)$ to provide

Table 1 Characteristics of evaluated recently graduated general practitioners from Lima, Peru $(N=434)$

\begin{tabular}{ll}
\hline Characteristics $^{\text {a }}$ & N (\%) \\
\hline Age (years old) $(n=422)$ & $222(52.6)$ \\
22 to 25 & $73(17.3)$ \\
26 & $127(30.1)$ \\
27 to 42 & \\
Gender $(n=434)$ & $188(43.3)$ \\
Males & $246(56.7)$ \\
Females & \\
University $(n=434)$ & $119(27.4)$ \\
USMP & $69(15.9)$ \\
UNMSM & $64(14.8)$ \\
URP & $56(12.9)$ \\
UCSur & $47(10.8)$ \\
UPSJB & $42(9.7)$ \\
UNFV & $24(5.5)$ \\
UPCH & $13(3.0)$ \\
UPC &
\end{tabular}

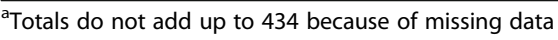
USMP Universidad San Martín de Porres, UNMSM Universidad Nacional Mayor de San Marcos, URP Universidad Ricardo Palma, UCSur Universidad Científica del Sur, UPSJB Universidad Privada San Juan Bautista, UNFV Universidad Nacional Federico Villareal, UPCH Universidad Peruana Cayetano Heredia, UPC Universidad Peruana de Ciencias Aplicadas 
non-pharmacological treatment, and 167 (39.2\%) to provide pharmacological treatment. With respect to schizophrenia, 263 (61.9\%) perceived themselves to be sufficiently competent to perform diagnosis, and 160 (37.2\%) to provide pharmacological treatment (Fig. 1). Missing data from the questions that aimed to assess competence ranged from 0.9 to $3 \%$.

From the evaluated GPs, 170 (41.6\%) perceived themselves to be adequately competent to perform the diagnosis, $153(36.1 \%)$ to provide non-pharmacological treatment, and $84(20.1 \%)$ to provide the pharmacological treatment for the four assessed mental health disorders. These proportions varied across universities (Table 2). Thus, in the case of diagnosis, percentages were higher among those who completed their undergraduate education at Universidad Nacional Mayor de San Marcos (UNMSM) (PR: 1.88, 95\% CI: 1.52-2.34) or Universidad Peruana Cayetano Heredia (UPCH) (PR: 1.62, 95\% CI: 1.18-2.24). While in the case of pharmacological treatment, percentages were higher among those who completed their undergraduate education at UNMSM (PR: 1.61, 95\% CI: $1.05-2.48$ ) or UPCH (PR: $1.98,95 \%$ CI: 1.13-3.44) (Table 2).

We also performed power analysis for all of the abovementioned comparisons, and found that, in the case of diagnostic and non-pharmacological treatment our power was less than $80 \%$ to find a PR of 1.5 for the following universities: UCSur, UPSJB, UNFV, UPCH, and UPC. In the case of pharmacological treatment, we found that all of the comparisons had a power of less than $80 \%$ to find a PR of 1.5. (Additional file 2).

When analyzing the primary outcomes as continuous variables using the Kruskal Wallis test, we found an association between the university and the perception of being competent to perform diagnosis using Kruskal Wallis test $(\mathrm{H}(7)=41.63$, $p$ value $\leq 0.001)$. We found differences between UNMSM and USMP $(p<0.001)$, URP $(p=0.005)$, UCSur $(p=0.002)$, UNFV $(p=0.020)$; and between UPCH and USMP $(p<0.001)$, URP $(p=0.016)$, $\operatorname{UCSur}(p=0.008)$, and UNFV $(p=0.033)$.

We also found an association between the university and the perception of being competent to perform pharmacological treatment $(\mathrm{H}(7)=22.79, p$ value $=$ $0.002)$. We found differences between UPCH and USMP $(p=0.006)$, URP $(p=0.004)$, and UCSur $(p=0.004)$.

On the other hand, we found no association between the university and the perception of being competent to provide non-pharmacological treatment $(\mathrm{H}(7)=11.54, p$ value $=0.117$ ) .

From the evaluated GPs, $75.9 \%$ recommended that coursework in psychiatry should have further training on patient treatment, $63.9 \%$ responded it should have

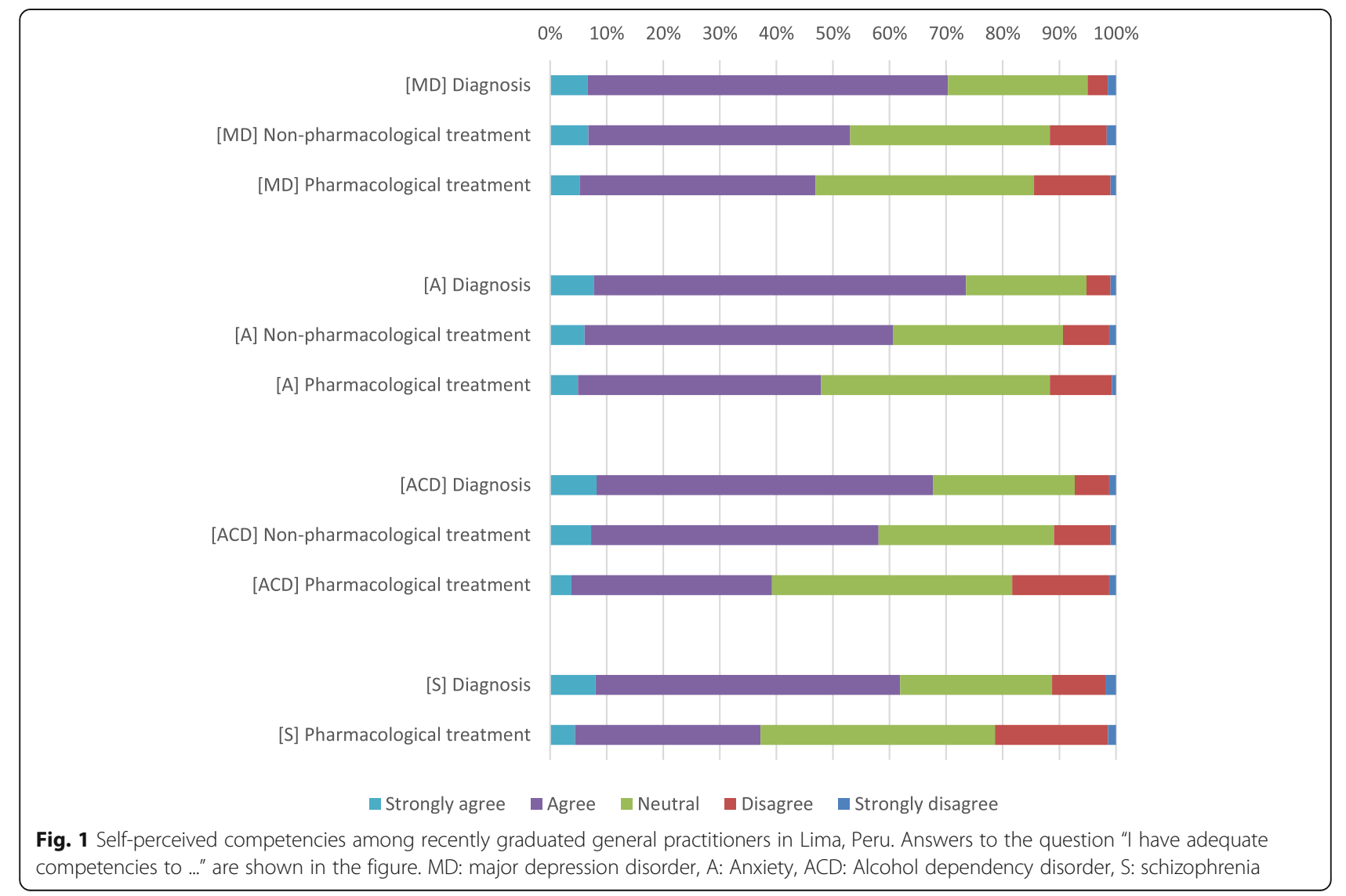


Table 2 University and percentage of general practitioners self-perceived as adequately competent to perform the diagnosis, nonpharmacological, and pharmacological treatment of four mental disorders ( $N=434)$

\begin{tabular}{|c|c|c|c|c|c|c|}
\hline \multirow[t]{2}{*}{ University } & \multicolumn{2}{|l|}{ Diagnosis } & \multicolumn{2}{|c|}{ Non-pharmacological treatment } & \multicolumn{2}{|c|}{ Pharmacological treatment } \\
\hline & $\mathrm{n} / \mathrm{N}(\%)$ & PR $(95 \% \mathrm{Cl})^{\mathrm{a}}$ & $\bar{n} / \mathrm{N}(\%)$ & PR $(95 \% C l)^{a}$ & $\mathrm{n} / \mathrm{N}(\%)$ & PR $(95 \% \mathrm{Cl})^{\mathrm{a}}$ \\
\hline USMP & $33 / 113(29.2)$ & $0.63(0.46-0.86)$ & $39 / 118(33.1)$ & $0.89(0.66-1.19)$ & 16/118 (13.6) & $0.60(0.36-0.99)$ \\
\hline UNMSM & $44 / 64(68.8)$ & $1.88(1.52-2.34)$ & 28/68 (41.2) & $1.17(0.85-1.61)$ & 20/68 (29.4) & $1.61(1.05-2.48)$ \\
\hline URP & 22/58 (37.9) & $0.90(0.63-1.28)$ & 22/63 (34.9) & $0.96(0.67-1.39)$ & 9/57 (15.8) & $0.76(0.40-1.44)$ \\
\hline UCSur & 16/54 (29.6) & $0.68(0.45-1.05)$ & $19 / 55(34.5)$ & $0.95(0.65-1.40)$ & 9/55 (16.4) & $0.79(0.42-1.49)$ \\
\hline UPSJB & 22/47 (46.8) & $1.14(0.82-1.59)$ & $15 / 44(34.1)$ & $0.94(0.61-1.45)$ & $11 / 45(24.4)$ & $1.25(0.72-2.18)$ \\
\hline UNFV & 14/38 (36.8) & $0.88(0.57-1.35)$ & $13 / 40(32.5)$ & $0.89(0.56-1.42)$ & $7 / 39(17.9)$ & $0.89(0.44-1.79)$ \\
\hline UPCH & $15 / 23(65.2)$ & $1.62(1.18-2.24)$ & $12 / 23(52.2)$ & $1.48(0.98-2.24)$ & $9 / 24(37.5)$ & $1.98(1.13-3.44)$ \\
\hline UPC & 4/12 (33.3) & $0.80(0.35-1.79)$ & $5 / 13(38.5)$ & $1.07(0.53-2.15)$ & $3 / 13(23.1)$ & $1.16(0.42-3.18)$ \\
\hline
\end{tabular}

${ }^{a}$ Each university group was compared with the rest of universities. Bold values denote statistical significance

USMP Universidad San Martín de Porres, UNMSM Universidad Nacional Mayor de San Marcos, URP Universidad Ricardo Palma, UCSur Universidad Científica del Sur, UPSJB Universidad Privada San Juan Bautista, UNFV Universidad Nacional Federico Villareal, UPCH Universidad Peruana Cayetano Heredia, UPC Universidad Peruana de Ciencias Aplicadas

more hours in the outpatient clinic, $60.8 \%$ responded that it should have more critical reading of scientific articles, $56.9 \%$ responded that it should have more contact with patients, and $28.7 \%$ that it should have more theoretical classes (Fig. 2).

\section{Discussion}

We found that round 7 of 10 of the GPs surveyed selfperceived as competent in the diagnosis and around 5 in 10 self-perceived competent in the treatment of the studied disorders. In general, around four in ten GPs self-perceived themselves as competent in performing diagnosis and in providing non-pharmacological treatment for all the studied mental health disorders, while two in ten GPs self-perceived themselves as competent to provide pharmacological treatment for all the studied mental health disorders. The self-perception of competence in performing diagnosis and in providing pharmacological treatment was greater among those who finished their undergraduate studies at UPCH and UNMSM than those who did not.

In Peru, the percentage of GPs with self-perception of adequate competencies for the diagnosis and treatment of mental health disorders was low. Previous studies found similar results: in Brazil, 10/24 (41.7\%) GPs detected that patients had mental health disorders when assessing a patient's mental status blinded to the results of the General Health Questionnaire (GHQ-12) [8]. In Peru, a study in 52 primary health care professionals which included 6 GPs and 19 psychiatrists, reported that $16 \%$ of participants reported "a great deal" of training on drugs and alcohol during undergraduate courses [16]. In Nepal, a study of 29 primary health care professionals (12 GPs) reported that clinical rotations in psychiatry during their undergraduate studies ranged from 0 to 15 days and were considered inadequate [13]. In Australia, a study in 256 GPs found that $19.4 \%$ felt very confident making the diagnosis of mental health disorders, and $94.7 \%$ felt very or somewhat confident in prescribing

\section{$\begin{array}{lllllllllll}0 \% & 10 \% & 20 \% & 30 \% & 40 \% & 50 \% & 60 \% & 70 \% & 80 \% & 90 \% & 100 \%\end{array}$}

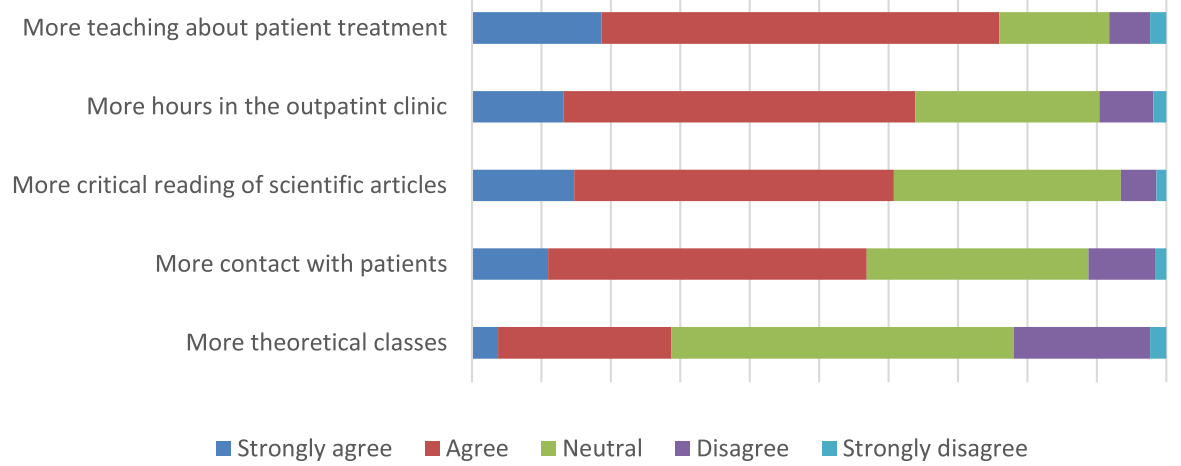

Fig. 2 Recommendations to improve the undergraduate courseware in psychiatry among recently graduated general practitioners in Lima, Peru 
antidepressants, $83.2 \%$ prescribing sedatives, and 50\% prescribing antipsychotics [14]. Compared to Australian physicians, Peruvian recently graduated physicians felt less confident in providing pharmacological treatment for the above-mentioned mental health disorders.

We found that those who studied in UNMSM and UPCH had a greater percentage of GPs that perceived themselves as sufficiently competent to perform an adequate diagnosis and treatment of the four mental health disorders studied. It should be noted that UNMSM and $\mathrm{UPCH}$ are the universities that usually occupy the top positions in the international university rankings in human medicine in Peru $[17,18]$ and in the Peruvian $\mathrm{Na}$ tional Medical Board Exam [19]. The differences found may be due to differences in the curricular structure of undergraduate mental health courses [20]. For instance, the psychiatry course in the UNMSM has $68 \mathrm{~h}$ of theoretical work and $136 \mathrm{~h}$ of practice, UPCH has $50 \mathrm{~h}$ of theoretical work and $100 \mathrm{~h}$ of practice, whereas other universities had fewer hours [21-23]. However, many other factors may be involved in these differences also.

Given that only four in ten GPs self-perceived as competent in providing non-pharmacological treatment for all the mental health disorders studied, and that there was no difference between competencies versus universities, we believe that these aspects of medical training are not thoroughly taught during medical school at all the universities included in the study.

It should be noted that the population of this study were GPs who studied at universities in Lima, the Peruvian city with the most psychiatrists [24]. However, in other cities in Peru the number of psychiatrists is very low, which may be affecting mental health education.

Our results have important implications for Peruvian medical schools, since according to Peruvian accreditation criteria for medical schools, GPs should be capable of diagnosing and treating mental health disorders [25]. For this reason, it is necessary to assess the characteristics of undergraduate curricula and mental health courses [26, 27]. These are functions attributed by law to the National Superintendence of Higher University Education (SUNEDU), a public body associated with the Ministry of Education [28].

Some authors have highlighted that undergraduate training in mental health should achieve the following competencies: adequate diagnosis and doctor-patient relationships, basic treatment principles, recognition of behaviors and/or emotions that interfere with care, and medical care based on a multidisciplinary team $[20,27]$. To do so, it would be important to consider the suggestions made by the respondents, such as enhancing the time for discussion of scientific articles and a clerkship in first level of care centers. Finally, due to the fact that most of recently graduated GPs in Peru perform their social service in rural settings, it is necessary to reinforce a systematic integration of these competencies with rural cultural features in mental health education [29].

Our results also have implications for the health care system, since health personnel with adequate competencies in mental health are needed in primary care facilities. Thus, GPs with these concerns prior to the SERUMS program could improve their ability and predisposition to manage patients with mental health disorders [11] and increase the number of referrals and the number of people identified and treated for mental health disorders [30]. For this to take place, courses that allow massive group training of health care personnel, including free virtual courses that address the treatment of mental health disorders [22], and the World Health Organization-driven Mental Health Gap Action Program (mhGAP) [2] could be used.

Some limitations must be considered: 1) we have assessed self-perceived competencies, which would not necessarily reflect the actual competencies of these GPs, as suggested previously for competencies not related to mental health [31]. However, we consider that the assessment of self-perceived competencies (the idea that each participant has regarding their own competence to perform a task) is important as it is closely related to motivation and outlook, which can directly influence their decisions about performing a task or not [32, 33]. 2) Our sample represented $23.0 \%$ of all GPs graduated in 2016 in Lima, and included different proportions of GPs from each university (see Additional file 1). Moreover, we were not able to compare characteristics of all graduated physicians in 2016 and our sample. However, since the vast majority of recently graduated GPs are applying for SERUMS program, it is possible that those who did not attend the conference in which our survey was performed were not informed about it or because they had other commitments, this not likely being a large bias in our results. 3) when analyzing the competencies by university were the GP finished their undergraduate studies, we have a small number of GPs from some universities such as UPC or UPCH, which translates into imprecision of the effect and low power. This prevents us from concluding that there is a lack of association between these universities and the outcomes.

Nonetheless, this is the first study to assess competencies in the valuation of mental health disorders in recently graduated GPs in Peru, who are the ones who provide mental health services in primary care facilities. Moreover, our results indicate a deficiency in Peruvian medical education that calls for intervention in the design and implementation of corresponding education. 


\section{Conclusion}

Among recently graduated GPs, the rate of self-perceived adequate competencies for diagnosis and management of mental health disorders was low. These proportions differed across universities. These results highlight the importance of assessing and implementing interventions in undergraduate medical education in mental health care in Peru.

\section{Supplementary information}

Supplementary information accompanies this paper at https://doi.org/10. 1186/s12909-019-1900-8.

Additional file 1. Recently graduated general practitioners included in the study compared to all recently graduated general practitioners from universities of Lima, Peru.

Additional file 2. Proportion of general practitioners self-perceived as adequately competent to perform the diagnosis, non-

pharmacological treatment, and pharmacological treatment of four mental disorders; and statistical power for the comparisons.

\section{Abbreviations}

95\% Cl: 95\% confidence intervals; GHQ-12: General Health Questionnaire; GP: General practitioners; mhGAP: Mental Health Gap Action Program; PR: Prevalence ratio; SERUMS: Urban Rural Marginal Internship Program; SUNEDU: National Superintendence of Higher University Education; UCSur: Universidad Científica del Sur; UNFV: Universidad Nacional Federico Villareal; UNMSM: Universidad Nacional Mayor de San Marcos;

UPC: Universidad Peruana de Ciencias Aplicadas; UPCH: Universidad Peruana Cayetano Heredia; UPSJB: Universidad Privada San Juan Bautista; URP: Universidad Ricardo Palma; USMP: Universidad San Martín de Porres

\section{Acknowledgements}

We would like to thank Wendy Nieto-Gutierrez, Susy Bazán-Ruiz, Edgar Ancajima More, and Danai Valladares-Garrido for their support in developing the research protocol. To Karla Ramos, Marcia E Hurtado-Villanueva, and María del Pilar Saenz-Naranjo for their support during the application of the surveys. To David Villarreal, Roger Abanto, Jose Alberto Arriola Vigo, and Jose Luis Avilez for reviewing the manuscript and making suggestions to improve it.

\section{Authors' contributions}

JHZT and ATR participated in the conception and design of the study. JHZT and KPB contributed with the acquisition of the data. All of the authors participated in the interpretation of data and the drafting of the article. All authors approved the final version of the manuscript.

\section{Funding}

This study was partially funded by the Sociedad Científica Médico Estudiantil Peruana (SOCIMEP), Peru. SOCIMEP did not participate in the design of the study and collection, analysis, and interpretation of data nor in writing the manuscript.

\section{Availability of data and materials}

The datasets used and/or analyzed during the current study are available on reasonable request from the corresponding author.

\section{Ethics approval and consent to participate}

This study was approved by the Institutional Research Board of the Hospital Nacional Docente Madre Niño - HONADOMANI (RCEl-40, Lima, Peru). This survey was voluntary and anonymous, every participant signed an informed consent form.

\section{Consent for publication}

Not applicable.

\section{Competing interests}

$\mathrm{JHZT}$ is continuing undergraduate studies at the Universidad Nacional Mayor de San Marcos. KPB, FIB and ATR have followed undergraduate studies at the Universidad de San Martín de Porres. JHZT, KPB, FIB and ATR have followed postgraduate studies at the Universidad Peruana Cayetano Heredia. FIB has followed postgraduate studies at the Universidad Nacional Mayor de San Marcos. JHZT, KPB and ATR are currently affiliated with the Universidad Peruana Cayetano Heredia.

\section{Author details}

${ }^{1}$ CRONICAS Center of Excellence for Chronic Diseases, Universidad Peruana Cayetano Heredia, Lima, Peru. ${ }^{2}$ SYNAPSIS Mental Health and Neurology, Non-Profit organization, Lima, Peru. ${ }^{3}$ Unidad de Investigación para la Generación y Síntesis de Evidencias en Salud, Universidad San Ignacio de Loyola, Lima, Peru. ${ }^{4}$ Universidad Continental, Lima, Peru.

Received: 22 March 2018 Accepted: 5 December 2019 Published online: 16 December 2019

\section{References}

1. National Institute of Mental Health. Global Leading Categories of Diseases/ Disorders. 2010. https://www.nimh.nih.gov/health/statistics/global/globalleading-categories-of-diseases-disorders.shtml. Accessed 17 May 2017.

2. WHO. Guidelines Approved by the Guidelines Review Committee. mhGAP. Mental Health Gap Action Programme: Scaling Up Care for Mental, Neurological and Substance Use Disorders. Geneva: World Health Organization; 2008.

3. Ministerio de salud. Personal Communication. In: Portal de Transparencia, editor; 2016.

4. Perú Poder Ejecutivo. Decreto Supremo Nº23-2001-SA. Reglamento de Estupefacientes Psicotrópicos Sujetas a Fiscalización Sanitaria. In: DIGEMID Lima, editor; 2001

5. Ministerio de Salud. Formulario Nacional de Medicamentos Esenciales. Lima: Dirección General de Medicamentos, Insumos y Drogas; 2008.

6. Congreso de la República del Perú. Decreto Ley 23330 Ley del Servicio Rural y Urbano Marginal de Salud - SERUMS. Lima: Congreso de la República; 1981.

7. Ministerio de Salud del Perú. Decreto Supremo 005-97-SA. Reglamento de la Ley 23330, Ley del Servicio Rural y Urbano Marginal de Salud - SERUMS. Lima: MINSA; 1997.

8. Goncalves DA, Fortes S, Campos M, et al. Evaluation of a mental health training intervention for multidisciplinary teams in primary care in Brazil: a pre- and posttest study. Gen Hosp Psychiatry. 2013;35(3):304-8.

9. Armstrong JC, Shoba R, Amali N, Gregory A. Knowledge and attitudes of doctors regarding the provision of mental health care in Doddaballapur Taluk, Bangalore Rural district, Karnataka. Int J Ment Health Syst. 2012;6(1):21.

10. Le Galudec M, Cornily G, Garlantezec R, Stephan F, Alavi Z, Walter M. Evaluation of GPs diagnostic knowledge and treatment practice in detection and treatment of early schizophrenia: a French postal survey in Brittany. Soc Psychiatry Psychiatr Epidemiol. 2013;49(1):69-77.

11. Abera M, Tesfaye M, Belachew T, Hanlon C. Perceived challenges and opportunities arising from integration of mental health into primary care: a cross-sectional survey of primary health care workers in south-West Ethiopia. BMC Health Serv Res. 2014;14:113.

12. Irfan M, Caldas de Almeida JM, Irfan UM, Raza UA, Farooq S. Schizophrenia diagnosis and treatment by general practitioners: a cross-sectional study in district Peshawar, Pakistan. JPMA J Pak Med Assoc. 2015:65(9):937-42.

13. Acharya B, Hirachan S, Mandel JS, van Dyke C. The mental health education gap among primary care providers in rural Nepal. Acad Psychiatry. 2016; 40(4):667-71.

14. Oakley Browne M, Lee A, Prabhu R. Self-reported confidence and skills of general practitioners in management of mental health disorders. Aust J Rural Health. 2007;15(5):321-6.

15. Acuna J, Rdz-Navarro K, Huepe G, Botto A, Carcamo M, Jimenez JP. Clinical skills of Chilean general practitioners for the management of depressive disorders. Revista medica de Chile. 2016;144(1):47-54.

16. Borba CP, Gelaye B, Zayas L, et al. Making strides towards better mental health care in Peru: results from a primary care mental health training. Int J Clin Psychiatry Ment Health. 2015;3(1):9-19. 
17. QS Top Universities. QS University Rankings: Latin America. 2016. https:// www.topuniversities.com/university-rankings/latin-american-universityrankings/2016. Accessed 17 May 2017.

18. QS Top Universities. QS University Rankings: by subject. 2017. https:/www. topuniversities.com/university-rankings/university-subject-rankings/2017/ medicine. Accessed 17 May 2017.

19. Asociación Peruana de Facultades de Medicina. Asociación Peruana de Facultades de Medicina. 2017. http://www.aspefam.org.pe/. Accessed 17 May 2017.

20. Smith RC, Laird-Fick H, D'Mello D, et al. Addressing mental health issues in primary care: an initial curriculum for medical residents. Patient Educ Couns. 2014;94(1):33-42.

21. Universidad Nacional Mayor de San Marcos. Silabo de Semiologia Psiquiatrica y Psiquiatria. In: Facultad de Medicina "San Fernando", editor; 2014.

22. Universidad de San Martin de Porres. Silabo de Psiquiatria. In: Facultad de Medicina Humana, editor; 2014

23. Universidad Peruana Cayetano Heredia. Silabo de Clinica Psiquiatrica. In: Facultad de Medicina "Alberto Hurtado", editor; 2014.

24. Miranda JJ, Diez-Canseco F, Araya R, et al. Transitioning mental health into primary care. Lancet Psychiatry. 2017;4(2):90-2.

25. Comisión para la Acreditación de Facultades y Escuelas de Medicina (CAFME). Estándares mínimos para la acreditación de facultades o escuelas de medicina. 2013

26. Rissman YZ, Khan CT, Isaac SK, Paiz JA, DeGolia SG. Developing a mental health curriculum to build capacity and improve access to mental health Care in Rural Guatemala. Acad Psychiatry. 2016;40(4):692-4.

27. Thomas S, Pai N, Dawes K, Wilson C, Williams V. Updating medical school psychiatry curricula to meet projected mental health needs. Australas Psychiatry. 2013;21(6):578-82.

28. Ministerio de educación. DECRETO SUPREMO No 012-2014-MINEDU. "Aprueban el Reglamento de Organización y Funciones de la Superintendencia Nacional de Educación Superior Universitaria SUNEDU". 2014.

29. Alarcon R, Suarez-Richards M, Sarabia S. Educación psiquiátrica y componentes culturales en la formación del médico: prespectivas latinoamericanas. Rev Peru Med Exp Salud Publica. 2014:31(3):557-65.

30. Gureje O, Abdulmalik J, Kola L, Musa E, Yasamy MT, Adebayo K. Integrating mental health into primary care in Nigeria: report of a demonstration project using the mental health gap action programme intervention guide. BMC Health Serv Res. 2015;15:242.

31. Davis DA, Mazmanian PE, Fordis M, Van Harrison R, Thorpe KE, Perrier L. Accuracy of physician self-assessment compared with observed measures of competence: a systematic review. Jama. 2006;296(9):1094-102.

32. Lai NM, Teng CL. Self-perceived competence correlates poorly with objectively measured competence in evidence based medicine among medical students. BMC Med Educ. 2011;11(1):25.

33. Kaduszkiewicz $H$, Wiese $B$, van den Bussche $H$. Self-reported competence, attitude and approach of physicians towards patients with dementia in ambulatory care: results of a postal survey. BMC Health Serv Res. 2008;8(1):54.

\section{Publisher's Note}

Springer Nature remains neutral with regard to jurisdictional claims in published maps and institutional affiliations.

Ready to submit your research? Choose BMC and benefit from:

- fast, convenient online submission

- thorough peer review by experienced researchers in your field

- rapid publication on acceptance

- support for research data, including large and complex data types

- gold Open Access which fosters wider collaboration and increased citations

- maximum visibility for your research: over $100 \mathrm{M}$ website views per year

At $\mathrm{BMC}$, research is always in progress.

Learn more biomedcentral.com/submissions 